\title{
FIBROMYALGIA TREATMENT USING MICROPHYSIOTHERAPY: AN OPEN-LABEL PILOT STUDY
}

Tatiana Dias Rosa de Matos ${ }^{1}$, Jozélio Freire de Carvalho $2, \star *$

1.Universidade da Bahia, Salvador (BA), Brazil.

*Corresponding author: jotafc@gmail.com

\section{BACKGROUND}

Fibromyalgia (FM) is a prevalent disease and often presents symptoms of anxiety and depression. Microphysiotherapy (MPT) is a novel alternative and complementary technique used to treat emotional disturbs using body work. Two studies on the use of MPT in FM were found. The objective was to evaluate the effects of MPT in FM patients.

\section{PATIENTS AND METHODS}

From 30 subjects selected, 18 were excluded; so, we have included 12 patients. All patients received three sessions of MPT. They were evaluated at preintervention and after 3 months of MPT treatment. Demographic data, anxiety and depression were evaluated by Beck inventories; sleep quality by the Pittsburgh scale and symptoms of dysbiosis by symptoms form.

\section{RESULTS}

Mean age was $50.8 \pm 11.8$ years old. Mean disease duration of 2 years (ranging from 3 months to 10 years). Analysis of the parameters after 3 months revealed no significant differences $(p>0.05)$ in Beck anxiety questionnaire, tender point counting, in Beck depression questionnaire, dysbiosis questionnaire and also Pittsburgh evaluation scale. Interesting, one patient had striking improvement of her clinical picture after MPT.

\section{CONCLUSION}

Treatment with MPT in patients with fibromyalgia does not seem to improve this disease. More studies are however needed to confirm these findings. 